\title{
La formación básica de docentes de educación infantil en lengua escrita y literatura. El caso de la Universidad Autónoma de Barcelona - UAB
}

\section{A formação básica de docentes de educação infantil em língua escrita e literatura. O caso da Universidade Autônoma de Barcelona - UAB}

\section{Basic training of early childhood education teachers in written language and literature. The Universidad Autónoma de Barcelona - UAB case}

\author{
Neus Real* \\ Maria Rosa Gil*
}

\begin{abstract}
RESUMEN
El presente artículo expone los resultados de una investigación llevada a cabo en la Universidad Autónoma de Barcelona (UAB) para evaluar la formación básica en didáctica de la lengua escrita y la literatura del alumnado de educación infantil. Mediante instrumentos iniciales y finales de diagnóstico y el contraste de los datos, se constata que dicha formación canaliza la integración de los principios socio-constructivistas del aprendizaje lingüístico y la adquisición de las bases de la educación literaria y de un conocimiento notable de los libros para las primeras edades, así como la aplicación de

* Universitat Autònoma de Barcelona. Departament de Didàctica de la Llengua i la Literatura, i de les Ciències Socials. Cerdanyola del Vallès - Bellaterra, Catalunya, Espanya. E-mail: neus.real@uab.cat.https://orcid.org/0000-0001-9049-4726.E-mail: mariarosa.gil@uab.cat.https:// orcid.org/0000-0003-1052-330X.
\end{abstract}


herramientas clave en el análisis e interpretación tanto de las producciones escritas de los niños como de los textos literarios. Y todo ello revierte en un cambio significativo de proyección didáctica. A pesar de este progreso, la investigación también indica la necesidad de trabajar más la proactividad de los niños, la figura del docente como mediador, la contextualización de las actividades de lengua escrita, la interpretación de las obras literarias y la definición de objetivos de aprendizaje en las actividades de literatura.

Palabras clave: Formación Básica Docente. Educación Infantil. Didáctica de la Lengua Escrita y la Literatura. Socio-constructivismo. Educación Literaria.

\title{
RESUMO
}

O presente artigo expõe os resultados de uma pesquisa realizada na Universidade Autônoma de Barcelona (UAB) para avaliar a formação básica em didática da língua escrita e da literatura das crianças da educação infantil. Através de ferramentas diagnósticas iniciais e finais e do contraste de dados, se verifica que esta formação canaliza a integração dos princípios socioconstrutivistas da aprendizagem linguística e a aquisição dos fundamentos da educação literária e de um conhecimento notável de livros para as primeiras idades, bem como a aplicação de ferramentas-chave na análise e interpretação de produções escritas de crianças e textos literários. E tudo isso se reverte em uma mudança significativa de projeção didática. Apesar desse avanço, a pesquisa indica também a necessidade de trabalhar mais a proatividade das crianças, a figura do professor como mediador, a contextualização das atividades da linguagem escrita, a interpretação dos trabalhos literários e a definição dos objetivos de aprendizagem nas atividades de literatura.

Palavras-chave: Formação Básica de Professores. Educação Infantil. Ensino da Língua Escrita e da Literatura. Socio-construtivismo. Educação Literária.

\begin{abstract}
This article presents the results of a research performed in the Autonomous University of Barcelona (UAB) to evaluate the basic training in didactics of written language and literature for students of early childhood education. Through initial and final diagnostic tools and the contrast of data, it was found that this training channels the integration of the socio-constructivist principles of linguistic learning and the acquisition of both the foundations of literary education and a remarkable knowledge of books destined to first ages, as well as the application of key tools in the analysis and interpretation of both children's written productions and literary texts. All this results in a significant change of didactic projection. Despite this progress, the research also highlights the need to work more on the proactivity of children, the figure
\end{abstract}


of the teacher as a mediator, contextualization of written language activities, interpretation of literary works and the definition of learning objectives in literature activities.

Keywords: Basic Teacher Training. Early Childhood Education. Written Language and Literature Teaching. Socio-constructivism. Literary Education.

\section{Introducción}

Conseguir la alfabetización universal sigue siendo un reto en las sociedades donde los niños aún no están completamente escolarizados. Pero también en aquellas, como la nuestra, en que lo están prácticamente en su totalidad, donde "la formación de docentes para todos los niveles del sistema educativo plantea permanentes desafíos referidos a los modos en que se produce el complejo proceso -con implicaciones en lo subjetivo, lo social y lo institucional- por el que un alumno deja esa condición y rápidamente se convierte en docente" (BOMBINI; LABEUR, 2013, p. 20). Si en la educación infantil "se configuran las bases de la formación literaria y del acceso al texto escrito" (COLOMER; DURÁN, 2001, p. 213), los futuros maestros deben salir de la universidad preparados para trabajar adecuadamente el primer aprendizaje de la lengua escrita y los fundamentos iniciales de la educación literaria. La formación básica docente debe cubrir los conocimientos esenciales sobre cómo los niños se apropian del código escrito y cómo promover su protagonismo en este sentido (TEBEROSKY, 2012) y sobre los libros para las primeras edades y la manera de movilizarlos en el aula a partir de unos objetivos definidos de progreso lector (COLOMER, 2005; CORRERO; REAL (eds.), 2017). Estas son las herramientas imprescindibles para que niños y niñas descubran la lengua escrita y la literatura, desarrollen el gusto por la escritura y la lectura y desplieguen unas incipientes habilidades productivas e interpretativas que les vayan permitiendo acceder a un corpus cada vez más amplio y complejo de textos escritos, los literarios de manera prioritaria. Todo ello, en un itinerario que se articule de forma progresiva desde las aulas de lactantes hasta el parvulario: que se abra con el desarrollo oral del sistema lingüístico y el descubrimiento del libro como objeto y se extienda, paso a paso, hasta los proyectos de lengua y literatura (FONS; PALOU, (coords.), 2016; CORRERO; REAL, 2016).

El Departamento de Didáctica de la Lengua y la Literatura y de las Ciencias Sociales de la Universidad Autónoma de Barcelona (UAB), responsable de la formación en enseñanza y aprendizaje de la lengua escrita y la literatura de los estudiantes de magisterio, aspira a cumplir estos objetivos. Con el fin de determinar 
si lo hace, el presente artículo ofrece los resultados de una primera investigación sobre Didáctica de la lengua escrita y la literatura en educación infantil, única asignatura obligatoria del Grado de Educación Infantil en la materia.

\section{Marco teórico}

Leer y escribir, más allá de dominar las relaciones sonido-grafía, son procesos inscritos en las funciones cognitivas de orden superior, que implican conocer el sistema de la lengua escrita y sus diferentes convenciones genéricas; en especial, las literarias. El término inglés literacy remite a la capacidad de uso pleno de la lectura y la escritura, y abarca tanto los conocimientos y actitudes necesarios para leer y escribir de manera significativa como la necesidad de involucrarse en ello. Si bien tal concepción es reconocida en todos los currículos escolares, no existe la misma unanimidad en las aulas; y menos aún en la etapa infantil.

El estudio Las condiciones del aprendizaje inicial de la lengua escrita: influencia de las prácticas vigentes en el aula y de los conocimientos previos de los alumnos (2009), liderado por Liliana Tolchinsky, permitió establecer cuatro tipos de prácticas vinculados a los dos perfiles básicos de más de 2.000 maestros de infantil y primaria de España (SÁNCHEZ; ALONSO (coords.), 2012): 1) instrucción explícita del código por parte del maestro; 2) fomento de la escritura infantil autónoma, con aceptación de escritos sin resolución correcta o convencional; 3) prioridad de los resultados por encima del proceso de aprendizaje, evitando el error, y 4) aprovechamiento de las situaciones emergentes del aula y las aportaciones de cada alumno para plantear casos en los que el uso de la lengua escrita permitía reflexionar sobre el funcionamiento del código. La primera y la tercera prácticas eran mucho más frecuentes en el perfil instruccional que en el situacional (RÍOS; FERNÁNDEZ; GALLARDO, 2012). La segunda y la cuarta, por el contrario, se daban mucho más en este último, pero representaban una escasa tercera parte de la acción docente. Esto podría explicar las desvirtuadas nociones sobre alfabetización del alumnado del Grado de Educación Infantil (PÉREZ, 2016), que oscilan entre la idea, reforzada por la propia experiencia, de que el aprendizaje surge de la copia, la caligrafía y la instrucción explícita del código por parte del docente y la idea de que el aprendizaje no debe encomendarse a los niños de esta etapa, así que carece de relación con prácticas de alfabetización inicial temprana, incluidas la explicación o la lectura de relatos. Los cruciales trabajos de Ferreiro y Teberosky (1979) ya aportaron información muy valiosa sobre cómo los niños conceptualizan 
el aprendizaje de la lectura y la escritura y cómo elaboran saberes de manera progresiva, poniendo en juego diversas capacidades hasta apropiarse del sistema de funcionamiento del código alfabético. Los probados niveles de aproximación infantil al código, contrastados y ampliados por nuevas investigaciones, impulsaron la aparición de numerosas prácticas escolares, entre ellas las del perfil situacional, basadas en los principios socio-constructivistas; es decir, centradas en el valor de una interacción maestro-niño con anclaje en el conocimiento de los niveles evolutivos infantiles y generadoras de actividades de uso real de la lengua escrita para que los aprendices participen de tareas letradas con materiales reales portadores de significado (TOLCHINSKY, 1990; DOMÍNGUEZ; BARRIO, 1997; FONS, 2004).

Por lo que respecta a la educación literaria, los estudios de las últimas décadas constatan de forma recurrente que "la creación de medioambientes ricos en libros y la socialización e intercambio entre lectores en las aulas conforma [...] una de las líneas de acción más relevantes para la formación lectora de nuestros niños y jóvenes" (MUNITA, en prensa). El papel de los docentes es clave para materializar esta línea de trabajo, pero las prácticas escolares tampoco resultan siempre las más idóneas: cuando maestros y maestras introducen la literatura infantil en las aulas, lo hacen sobre todo a partir de criterios sesgados y mediante unas actividades poco propias de la educación literaria o poco innovadoras (WOLLMAN-BONILLA, 1998; CARDOSO; SEPÚLVEDA, 2015; SARDINHA, AZEVEDO; RATO, 2015). Y es que los estudiantes de magisterio a menudo no salen lo bastante preparados de la facultad para ejercer de puente entre la literatura infantil y los niños (CERRILLO; YUBERO, 2007; COLOMER, 2013). Las investigaciones exponen limitaciones importantes en cuanto a textotecas internas, reducidas habilidades interpretativas, una concepción simplista de los libros para las primeras edades y una comprensión superficial de su potencial didáctico (SILVA-DÍAZ, 2001; DÍAZ ARMAS, 2008; CREMIN et al., 2011; MORÓN; MARTÍNEZ, 2014; MUNITA, 2014). Los trabajos que apuntan soluciones a esta problemática señalan la óptima formación básica en literatura infantil y educación literaria como el eje del cambio en los cuatro ámbitos (SHAW; DVORAK; BATES, 2007; WARMACK, 2007; DELEUZE, 2009).

\section{Contexto, objetivos y metodología de la investigación}

Cuando en la Facultad de Ciencias de la Educación de la UAB se diseñaron los actuales planes de estudios, Didáctica de la lengua escrita y la literatura en 
educación infantil (asignatura de 7 créditos ECTS de tercer curso) se concibió sobre los principios del socio-constructivismo y la educación literaria con el fin de que los futuros maestros adquirieran las herramientas didácticas necesarias para acompañar y estimular la entrada al mundo letrado y formar lectores (ver guía docente en $<$ http://www.uab.cat/guiesdocents/2017-18/g103680a2017-18iSPA. pdf $>$ ). Con 53 horas de clase presenciales (18 de teoría en grupo íntegro y 35 de seminario en grupo partido), 35 horas de actividades supervisadas (tutorías presenciales y virtuales) y 87 horas de actividad autónoma (lectura de bibliografía, elaboración de trabajos, etc.) por alumno, la asignatura aspira a ofrecer conocimientos y experiencias prácticas de trabajo escolar en lengua escrita y literatura a partir de aquellos principios. Durante el año académico 2017-2018 se ha llevado a cabo una investigación exploratoria de tipo descriptivo para valorar los resultados efectivos de tal propósito. El trabajo, situado en el marco de los estudios de caso, pretende comprobar si aumenta - y cuánto - la consciencia sobre los procesos de enseñanza y aprendizaje de la lengua escrita y la literatura y sobre la intensa actividad mental que requiere apropiarse de objetos culturales tan complejos; $y$ muy en especial, establecer el progreso cuantitativo y cualitativo de los conocimientos generales, las habilidades analíticas e interpretativas y las capacidades de programación del alumnado en ambos ámbitos.

Los sujetos participantes fueron los 79 matriculados de uno de los dos grupos que realizaban la asignatura. Este focus group estaba integrado por 77 mujeres y 2 hombres de entre 20 y 21 años. Se trataba, por un lado, de 66 alumnos del Grado de Educación Infantil más 1 alumna vasca de intercambio (ninguno de ellos con formación previa, en $1^{\circ}$ y $2^{\circ}$ cursos, en didáctica de la lengua escrita y la literatura) y, por otro, de 12 alumnas del Doble Grado de Educación Infantil y Primaria, que habían cursado Lenguajes y currículos del Grado de Educación Primaria, equivalente a Didáctica de la lengua escrita y la literatura en educación infantil, el año anterior (ver guía docente en $<\mathrm{http}$ :// www.uab.cat/guiesdocents/2017-18/g102076a2017-18iSPA.pdf $>$ ). Los datos se han recabado mediante instrumentos de diagnóstico iniciales y finales, constituidos por preguntas y ejercicios prácticos. Los estudiantes debían responder a cuatro cuestiones relativas a saberes generales: ¿Cómo te imaginas la enseñanza-aprendizaje de la lengua escrita en educación infantil?, ¿Qué es la educación literaria en educación infantil?, ¿Qué libros para niños de 0 a 6 años conoces? y ¿Qué crees que se ha hecho en el aula para conseguir esta producción infantil sobre "Los tres cerditos"? (ver Imagen 1). Y también analizar el texto escrito de tal producción, anotar los aspectos literarios principales del álbum de Maurice Sendak Donde viven los monstruos (previamente leído en voz alta por una profesora con el apoyo de la proyección de imágenes) y, finalmente, proponer a una clase con niños de 5 y 6 años tanto una actividad para motivar a escribir 
como una actividad relacionada con el libro de Sendak. Los diagnósticos se realizaron por sorpresa el primer y el último día de clase, en el segundo caso sin conocimiento de que coincidirían exactamente con los primeros.

\section{IMAGEN 1: PRODUCCIÓN INFANTIL ESPONTÁNEA QUE ELALUMNA- DO DEBÍA CONSIDERAR}

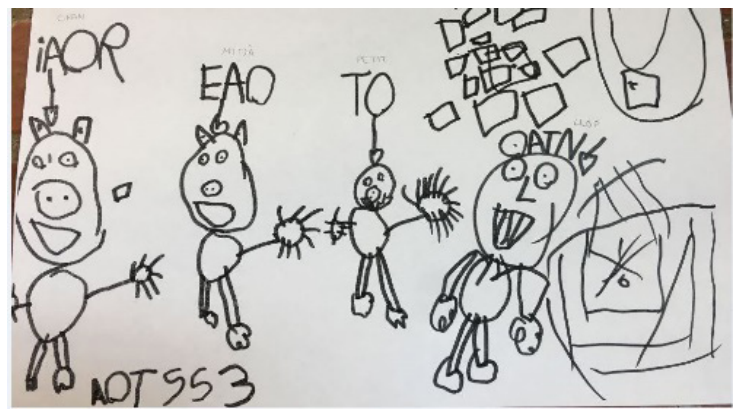

FUENTE: Escuela Francesc Aldea (Terrassa). Curso 2017-18. Clase de 5 años.

Las respuestas se han categorizado en una escala de diferentes ítems dentro de cada uno de los ocho bloques del diagnóstico: 1) concepción del proceso de aprendizaje del lenguaje escrito; 2) concepto de educación literaria; 3) nociones sobre el origen de las producciones gráficas infantiles; 4) conocimiento sobre los libros para niños de 0 a 6 años; 5) análisis de producciones escritas infantiles; 6) análisis literario; 7) programación de actividades de aprendizaje de la lengua escrita, y 8) programación de actividades de formación literaria. Los datos obtenidos se presentan en tablas de elaboración propia. Su discusión parte del análisis cuantitativo pero incorpora matices cualitativos mediante la ejemplificación de respuestas, y contrasta los saberes y capacidades del alumnado antes y después de realizar la asignatura.

\section{Presentación y discusión de resultados}

Las diferencias entre las respuestas iniciales y finales de los estudiantes exponen una progresión incuestionable de los conocimientos generales y las habilidades específicas en lengua escrita y literatura de los alumnos, lo cual explica significativos cambios en sus creencias y proyección didáctica como futuros docentes. Veámoslo punto por punto. 
Conocimientos generales: 1. El aprendizaje del lenguaje escrito

TABLA 1. EL APRENDIZAJE DEL LENGUAJE ESCRITO. Nº DE RESPUESTAS CON PORCENTAJES

\begin{tabular}{|l|l|l|l|l|l|l|l|l|}
\hline & \multicolumn{2}{|l|}{ C1. Proceso de aprendizaje } & \multicolumn{2}{l|}{ C2. Papel del aprendiz } & \multicolumn{2}{l|}{ C3. Materiales } & \multicolumn{2}{l|}{ C4. Rol del docente } \\
\cline { 2 - 9 } & $\begin{array}{l}\text { C1.S1 } \\
\text { Linealy } \\
\text { progresivo }\end{array}$ & $\begin{array}{l}\text { C1.S2 } \\
\text { Más complejo }\end{array}$ & $\begin{array}{l}\text { C2.S1 } \\
\text { Pasivo / receptivo }\end{array}$ & $\begin{array}{l}\text { C2.S2 } \\
\text { Más activo }\end{array}$ & $\begin{array}{l}\text { C3.SI } \\
\text { Especificos, } \\
\text { muy escolares }\end{array}$ & $\begin{array}{l}\text { C3.S2 } \\
\text { De la vida } \\
\text { real }\end{array}$ & $\begin{array}{l}\text { C4.SI } \\
\text { Directivo }\end{array}$ & $\begin{array}{l}\text { C4.S2 } \\
\text { Mediador }\end{array}$ \\
\hline$D I$ & $7=8,8 \%$ & $2=2,5 \%$ & $13=16,4 \%$ & $14=17,7 \%$ & $23=29,1 \%$ & $8=10,1 \%$ & $9=11,3 \%$ & $3=3,7 \%$ \\
\hline$D F$ & $2=2,5 \%$ & $21=26,5 \%$ & $1=1,2 \%$ & $22=27,8 \%$ & $0=0 \%$ & $14=17,7 \%$ & $0=0 \%$ & $19=24 \%$ \\
\hline
\end{tabular}

CLAVES - DI: Diagnóstico inicial. DF: Diagnóstico Final. C: Categorización de respuestas. S: Subcategorización de respuestas

Antes de cursar la asignatura, dos tercios de los estudiantes (el 65,6\% resultante de la suma de los porcentajes de S1) se situaban en el perfil instruccional: concebían la entrada a la alfabetización como un proceso de aprendizaje lineal y progresivo - simple, detallado, derivado del oral, centrado en la instrucción explícita del código y el aprendizaje de sonidos y letras como un requisito indispensable - en el que los niños tienen un rol pasivo y receptivo (simplemente reproductor) y el docente lo dirige todo - explica, propone, dice, muestra, pide... - con el apoyo de unos materiales de trabajo específicos, muy escolares. Si el tercio restante (34 \%) se situaba en el perfil situacional era por haber cursado la asignatura equivalente del Grado de Educación Primaria o más probablemente, dado que más de la mitad de estudiantes optaban por un papel activo de los aprendices, a causa de la insistencia en la importancia del protagonismo de los niños en los procesos de aprendizaje que caracteriza las asignaturas de $1^{\circ}$ y $2^{\circ}$ del Grado de Educación Infantil de la UAB. Al finalizar, por lo contrario, un $96 \%$ de las respuestas (resultado de sumar los porcentajes de S2) demostraban la capacidad adquirida para disertar sobre la complejidad del proceso de aprendizaje en las primeras edades, sobre el necesario compromiso de los docentes con los alumnos procedentes de entornos poco alfabetizados o sobre la actividad de los aprendices en el contacto con materiales reales y portadores de significado mediados por los adultos. El cambio de conocimientos es espectacular; pero además, respuestas como "primero los niños aprenden las letras y los sonidos, después a unir los sonidos para formar palabras y poder, más tarde, relacionar esas palabras con las imágenes", registradas en el cuestionario inicial, desaparecieron para ser sustituidas por explicaciones como "las maestras deberán leer y escribir a menudo para los niños, resolver con ellos cuestiones prácticas que acontezcan en la actividad diaria del aula y que reclamen el uso del lenguaje escrito y, también, proporcionarles experiencias gozosas que les permitan comprender los textos que se les lean", lo cual evidencia un giro de cinto ochenta grados en las creencias y posición del alumnado. 
Conocimientos generales: 2. La educación literaria

TABLA2. LA EDUCACIÓN LITERARIA. Nº DE RESPUESTAS CON PORCENTAJES

\begin{tabular}{|l|l|l|l|l|l|l|}
\hline & $\begin{array}{l}\text { C1: Definición } \\
\text { completa }\end{array}$ & $\begin{array}{l}\text { C2: Definición } \\
\text { parcial }\end{array}$ & $\begin{array}{l}\text { C3: Idea aproximada } \\
\text { con alguna precisión }\end{array}$ & $\begin{array}{l}\text { C4: Idea aproximada } \\
\text { sin ninguna precisión }\end{array}$ & $\begin{array}{l}\text { C5: Idea } \\
\text { desvirtuada }\end{array}$ & C6: NS / NC \\
\hline DI & $1=1,3 \%$ & $15=19 \%$ & $7=8,8 \%$ & $51=64,5 \%$ & $5=6,3 \%$ & $0=0 \%$ \\
\hline DF & $49=62 \%$ & $28=35,4 \%$ & $1=1,3 \%$ & $0=0 \%$ & $1=1,3 \%$ & $0=0 \%$ \\
\hline
\end{tabular}

CLAVES - DI: Diagnóstico inicial. DF: Diagnóstico Final. C: Categorización de respuestas. NS / NC: No sabe / no contesta.

En el diagnóstico inicial, tan solo 1 estudiante de Doble Grado fue capaz de definir de manera adecuada y completa la educación literaria infantil al escribir que consistía en "llevar los libros infantiles al aula para fomentar el gusto por la lectura y enseñar a los niños a entender los textos, cada vez más y mejor"; 15 alumnas (un 19\% dentro del cual se hallaban las 11 restantes de Doble Grado) pudieron proporcionar una definición parcial del concepto - es decir, se refirieron a los libros o a los cuentos, por un lado, y al desarrollo del gusto por la lectura o de las habilidades interpretativas, por otro-, y 7 (un 8,8\%) aportaron una idea aproximada de tal noción anotando los libros infantiles, la literatura en general o los cuentos en particular, más alguna precisión relativa al desarrollo del gusto por la lectura o de las habilidades interpretativas. Más de dos tercios de los alumnos, sin embargo, expusieron una idea muy vaga o errónea al respecto: o bien se limitaron a consignar la relación con la literatura de la educación literaria $(64,5 \%)$ o bien desvirtuaron completamente su sentido y función $(6,3 \%)$, refiriéndose por ejemplo al uso de los libros para el aprendizaje de hábitos como "ir al baño". Además de la poca precisión en las formulaciones de esta mayoría (en algunos casos con explicitación de no saber, pero tratar de responder "más o menos"), la confusión entre libro o literatura y "cuento" fue generalizada. Después de realizar la asignatura, tan solo 2 de los 79 estudiantes resultaron incapaces de proporcionar una definición completa o parcial del concepto de educación literaria. Estas definiciones fueron producidas respectivamente por 49 y 28 alumnos (un $62 \%$ y un 35,4\%), aunque en el segundo caso la atribución de parcialidad responde mayoritariamente al hecho de no incluir el desarrollo del gusto por la lectura, implícito en un número importante de respuestas pero considerado no incluido si no había referencia explícita. Una gran parte del alumnado, por consiguiente, integró una noción clara de lo que supone la educación literaria de los 0 a los 6 años, con lo cual dio el paso significativo previsto en su formación como futuros mediadores en este sentido. Solo 2 personas repitieron el error de equiparar libros y "cuentos". 
Conocimientos generales: 3. Origen de las producciones gráficas infantiles

TABLA 3. ORIGEN DE LAS PRODUCCIONES GRÁFICAS INFANTILES. N DE RESPUESTAS CON PORCENTAJES

\begin{tabular}{|l|l|l|l|l|l|}
\hline & $\begin{array}{l}\text { Cl.Contextos de } \\
\text { aula favorables a la } \\
\text { alfabetización y la } \\
\text { expresión }\end{array}$ & $\begin{array}{l}\text { C2.Lectura del cuento } \\
\text { y posteriores tertulias } \\
\text { literarias }\end{array}$ & $\begin{array}{l}\text { C3.Trabajo } \\
\text { especifico con el } \\
\text { cuento después de } \\
\text { su explicación }\end{array}$ & $\begin{array}{l}\text { C4.Petición } \\
\text { explícita del } \\
\text { docente }\end{array}$ & $\begin{array}{l}\text { C5. Prácticas } \\
\text { vinculadas a la } \\
\text { experimentación del } \\
\text { trazo y la copia }\end{array}$ \\
\hline$D I$ & $2=2,5 \%$ & $6=7,5 \%$ & $31=39,2 \%$ & $13=16,4 \%$ & $27=34,1 \%$ \\
\hline$D F$ & $10=12,6 \%$ & $21=26,5 \%$ & $33=41,7 \%$ & $15=18,9 \%$ & $0=0 \%$ \\
\hline
\end{tabular}

CLAVES - DI: Diagnóstico inicial. DF: Diagnóstico Final. C: Categorización de respuestas.

Antes de la asignatura, únicamente el 10\% del alumnado concebía que las producciones infantiles pudieran surgir espontáneamente al derivarse de contextos favorables a la expresión y la alfabetización, así como de la relación con los libros en el aula. Respuestas como "se están trabajando las formas circulares y las rectas a partir de los dibujos", "se están trabajando las mayúsculas, el trazo y la motricidad fina" o "el niño practica y copia lo que la maestra dibujó y escribió en la pizarra", demostraron la creencia, en el $34,1 \%$ de los casos, de que el dibujo de Los tres cerditos era fruto de prácticas relacionadas con el trazo y la copia. Una mayoría $(39,2 \%)$ afirmó que su origen debía encontrarse o bien en una petición explícita del docente o bien en un trabajo específico una vez explicado el relato. Después del curso, sin embargo, desaparecieron por completo aquel tipo de respuestas y aumentó en un $10 \%$ (del 2,5\% al 12,6\%) la consideración de que determinados productos aparecen como resultado de la mediación y la interacción con los libros (es decir, con materiales reales portadores de sentido). La modificación de los extremos representados por las categorías $\mathrm{C} 1$ y C5 resulta relevante respecto al cambio de ideas sobre aquello que motiva las producciones infantiles espontáneas con dibujos y escrituras. Al principio casi no cabía en el imaginario del alumnado que se tratara de producciones no inducidas por el docente; al final, esta visión se había transformado. En especial en relación a C2, con un incremento del 19\% respecto al diagnóstico inicial (del 7\% al 26,5\%), ya que proliferaron las argumentaciones que resaltaban las consecuencias de conversar con los niños sobre los relatos explicados o leídos (sobre los hechos de las historias o las características de sus personajes, por ejemplo). El trabajo relativo a la educación literaria muestra aquí, sin duda, sus efectos. Ahora bien, el porcentaje más elevado de respuestas $(41,7 \%)$ siguió centrándose en la idea de que la mayoría de productos infantiles son fruto de la petición del maestro o consecuencia de las actividades que él introduce en el aula: que los niños sean proactivos o tomen la iniciativa en la producción de dibujos o escrituras seguía 
estando lejos de sus concepciones. Parece que el peso de la tradición escolar -y de las propias experiencias - mantuvo una influencia decisiva que la asignatura no consiguió contrarrestar.

Conocimientos generales: 4. Títulos infantiles para lectores de 0 a 6 años

TABLA 4. TÍTULOS INFANTILES PARA LECTORES DE 0 A 6 AÑOS. No DE RESPUESTAS CON PORCENTAJES

\begin{tabular}{|l|l|l|l|l|l|l|}
\hline & $\begin{array}{l}\text { C1: } 10 o+ \\
\text { variados }\end{array}$ & $\begin{array}{l}\text { C2: } 5-9 \\
\text { variados }\end{array}$ & $\begin{array}{l}\text { C3: } 5-9 \text { no } \\
\text { variados }\end{array}$ & $\begin{array}{l}\text { C4: 1-5 } \\
\text { variados }\end{array}$ & $\begin{array}{l}\text { C5: 1-5 no } \\
\text { variados }\end{array}$ & C6: NS / NC \\
\hline$D I$ & $3=3,8 \%$ & $17=21,5 \%$ & $6=7,6 \%$ & $24=30,4 \%$ & $27=34,2 \%$ & $2=2,5 \%$ \\
\hline$D F$ & $79=100 \%$ & $0=0 \%$ & $0=0 \%$ & $0=0 \%$ & $0=0 \%$ & $0=0 \%$ \\
\hline
\end{tabular}

CLAVES - DI: Diagnóstico inicial. DF: Diagnóstico Final. C: Categorización de respuestas. NS / NC: No sabe / no contesta.

Antes de cursar la materia, los conocimientos sobre los libros para prelectores y primeros lectores eran muy limitados. Únicamente 3 personas de Doble Grado pudieron anotar 10 títulos o más, y variados - de tipologías, géneros y/o autores distintos y dirigidos a diferentes edades dentro de la primera infancia -. Si bien 17 estudiantes (las 9 alumnas restantes de Doble Grado entre ellos) anotaron de 5 a 9 títulos variados, conocer entre 5 y 8 obras - cifras predominantes - no puede considerarse un gran saber sobre literatura infantil; especialmente porque los títulos se limitaban, con escasas excepciones, a los clásicos populares - Caperucita Roja, Los tres cerditos, Cenicienta, La Bella Durmiente, etc. (en algún caso, explícitamente en versiones de Disney) - y a unos pocos libros álbum (¿A qué sabe la luna? y Elmer, de forma destacada), descubiertos durante las prácticas de $2^{\circ}$ curso en centros educativos. El 64,6\% que no llegó a 10 obras también remitió, en su mayoría, a la narrativa de tradición oral, y en segundo término, a los álbumes mencionados. Un $2,5 \%$ no consiguió escribir ni una referencia (dejando la respuesta en blanco). Después de realizar la asignatura, en cambio, el 100\% del alumnado pudo referirse a un mínimo de 10 libros infantiles; en realidad, 17 títulos fue la mediana de anotaciones (llegando 19 personas a consignar 20 títulos o más), y seguramente habrían anotada más de haber más espacio disponible para la respuesta. Más allá de las cifras, la diversidad nominal y genérica de las referencias, que incluían obras leídas en clase pero también muchas procedentes de los trabajos individuales y colectivos, y libros-juego, pop-ups, imaginarios, troquelados, libros informativos, poemarios, libros álbum, etc. (a menudo explicitando las tipologías), muestra el incremento cuantitativo y cualitativo de los saberes correspondientes. 
Habilidades especificas: 1. Análisis e interpretación de producciones escritas infantiles

TABLA 5. ANÁLISIS E INTERPRETACIÓN DE PRODUCCIONES ESCRITAS INFANTILES. N ${ }^{\circ}$ DE RESPUESTAS CON PORCENTAJES

\begin{tabular}{|l|l|l|l|l|l|}
\hline & $\begin{array}{l}\text { C1.Se les atribuye } \\
\text { sentido y se interpretan } \\
\text { adecuadamente a la } \\
\text { luz de los procesos } \\
\text { evolutivos }\end{array}$ & $\begin{array}{l}\text { C2.Se les atribuye } \\
\text { sentido y se interpretan } \\
\text { a la luz de los procesos } \\
\text { evolutivos, pero de forma } \\
\text { confusa o incorrecta }\end{array}$ & $\begin{array}{l}\text { C3. Se les atribuye } \\
\text { sentido pero no se } \\
\text { interpretan a la } \\
\text { luz de los procesos } \\
\text { evolutivos }\end{array}$ & $\begin{array}{l}\text { C4. Simplemente } \\
\text { se describen o se } \\
\text { consideran meros } \\
\text { complementos de } \\
\text { los dibujos }\end{array}$ & $\begin{array}{l}\text { C5erpretan } \\
\text { interpo azarosas, } \\
\text { completas o } \\
\text { incomeas } \\
\text { erróneas }\end{array}$ \\
\hline DI & $2=2,5 \%$ & $6=7,5 \%$ & $13=16,4 \%$ & $34=43,0 \%$ & $24=30,3 \%$ \\
\hline$D F$ & $67=84,8 \%$ & $12=15,1 \%$ & $0=0 \%$ & $0=0 \%$ & $0=0 \%$ \\
\hline
\end{tabular}

CLAVES - DI: Diagnóstico inicial. DF: Diagnóstico Final. C: Categorización de respuestas.

Los datos evidencian que en este apartado es donde los sujetos participantes consiguieron mayor progresión y avances conceptuales. En el ejercicio previo a la asignatura solamente un $10 \%$ integrado por estudiantes de Doble Grado fue capaz de analizar las escrituras que acompañaban al dibujo y atribuirles significado a la luz de los procesos evolutivos. El 90\% restante o bien ignoró esos procesos para interpretar las producciones escritas $(16,4 \%)$ o bien no las analizó: se limitó a describirlas o considerarlas un simple complemento de las ilustraciones (43\%) y a valorarlas como azarosas, incompletas o erróneas (30,3\%). En el diagnóstico final, en cambio, el 100\% llevó a cabo su análisis e interpretación, una diferencia colosal confirmada por el hecho de que una mayoría muy destacada (el $84,8 \%$ ) lo hiciera evaluándolas en el marco de investigaciones relevantes para indicar el estadio evolutivo al que podrían corresponder. Aunque un $15,1 \%$ de sus interpretaciones fueron confusas o incorrectas, es significativo que la equivocada idea de las escrituras infantiles como subsidiarias al dibujo, azarosas, incompletas o erróneas se eliminara del horizonte de creencias del alumnado.

Habilidades especificas: 2. Identificación, análisis e interpretación de aspectos literarios

TABLA 6. IDENTIFICACIÓN, ANÁLISIS E INTERPRETACIÓN DE ASPECTOS LITERARIOS. $\mathrm{N}^{\mathrm{O}}$ DE RESPUESTAS CON PORCENTAJES

\begin{tabular}{|l|l|l|l|l|l|l|}
\hline & $\begin{array}{l}\text { C1: } 60+ \\
\text { adecuados y } \\
\text { explicados }\end{array}$ & $\begin{array}{l}\text { C2: } 6 \text { o }+ \\
\text { adecuados y } \\
\text { no explicados }\end{array}$ & $\begin{array}{l}\text { C3: } 1-5 \\
\text { adecuados y } \\
\text { explicados }\end{array}$ & $\begin{array}{l}\text { C4: } 1-5 \\
\text { adecuados y } \\
\text { no explicados }\end{array}$ & $\begin{array}{l}\text { C5: 1-5 no } \\
\text { adecuados }\end{array}$ & C6: NS / NC \\
\hline$D I$ & $0=0 \%$ & $0=0 \%$ & $8=10 \%$ & $45=57 \%$ & $15=19 \%$ & $11=14 \%$ \\
\hline$D F$ & $8=10 \%$ & $19=24 \%$ & $27=34,2 \%$ & $25=31,6 \%$ & $0=0,0 \%$ & $0=0,0 \%$ \\
\hline
\end{tabular}

CLAVES - DI: Diagnóstico inicial. DF: Diagnóstico Final. C: Categorización de respuestas. NS / NC: No sabe / no contesta. 
En la esfera de la identificación, el análisis y la interpretación de aspectos literarios se expusieron algunas de las debilidades iniciales más considerables del alumnado; de ahí el vacío de respuestas en $\mathrm{C} 1$ y C2. Antes del curso, 26 estudiantes o bien fueron incapaces de escribir nada sobre los aspectos literarios destacables de Donde viven los monstruos, llegando a explicitar en algunos casos no tener idea de lo que eran tales aspectos (14\%), o bien anotaron menos de 5 que, además, estaban fuera de lugar (19\%); por ejemplo "la buena entonación”, confundiendo así el acto de lectura en voz alta con el análisis de la obra. Un $57 \%$ identificaron entre 1 y 5 aspectos literarios del álbum (el narrador en tercera persona, el protagonista infantil, los monstruos como personajes, la presencia de ilustraciones y el tema o el mensaje), pero sin referirse a su sentido en el conjunto de la construcción narrativa. Tan solo un 10\% detectó y explicó la relación clave entre texto e imagen o la combinación esencial de realidad y fantasía para el despliegue del relato y su sentido. Al final de la asignatura, por el contrario, el $100 \%$ de los estudiantes fue capaz de anotar entre 3 y 5 aspectos literarios de la obra. Si bien un 31,6\% se limitó a la constatación, un 34,2\% desglosó su significado. De los 27 alumnos que identificaron 6 o más aspectos, no obstante, solamente un $10 \%$ los explicó suficientemente. A pesar del progreso global evidente, que un 55,7\% no pudiera más que nombrar los componentes narrativos indica la necesidad de reforzar la dimensión interpretativa del trabajo analítico con una evaluación más profunda de la contribución significativa de cada aspecto literario.

\section{Habilidades especificas: 3. Programación de actividades de aprendizaje del lenguaje escrito}

TABLA 7. ACTIVIDADES DE APRENDIZAJE DEL LENGUAJE ESCRITO. N DE RESPUESTAS CON PORCENTAJES

\begin{tabular}{|l|l|l|l|l|l|}
\hline & $\begin{array}{l}\text { C1. Propuesta } \\
\text { contextualizada } \\
\text { e interdisciplinar, } \\
\text { con énfasis en } \\
\text { distintos aspectos } \\
\text { del lenguaje escrito }\end{array}$ & $\begin{array}{l}\text { C2. Propuesta } \\
\text { contextualizada } \\
\text { con énfasis en } \\
\text { algunos aspectos } \\
\text { del lenguaje } \\
\text { escrito }\end{array}$ & $\begin{array}{l}\text { C3. Propuesta poco } \\
\text { contextualizada } \\
\text { pero con énfasis en } \\
\text { algunos aspectos del } \\
\text { lenguaje escrito }\end{array}$ & $\begin{array}{l}\text { C4. Propuesta } \\
\text { descontextualizada } \\
\text { con énfasis en } \\
\text { aspectos relativos } \\
\text { al lenguaje escrito }\end{array}$ & $\begin{array}{l}\text { C5. Propuesta } \\
\text { descontextualizada } \\
\text { con énfasis exclusivo } \\
\text { en el aprendizaje } \\
\text { del código y la } \\
\text { caligrafia }\end{array}$ \\
\hline DI & $3=3,7 \%$ & $10=12,6 \%$ & $16=20,2 \%$ & $20=25,3 \%$ & $30=37,9 \%$ \\
\hline$D F$ & $16=20,2 \%$ & $26=32,9 \%$ & $32=40,5 \%$ & $5=6,3 \%$ & $0=0 \%$ \\
\hline
\end{tabular}

CLAVES - DI: Diagnóstico inicial. DF: Diagnóstico Final. C: Categorización de respuestas.

Antes del curso, el tipo de actividades que la mayor parte del alumnado (el 63,2\% resultante de la suma de $\mathrm{C} 4$ y C5) diseñó para alcanzar los objetivos de alfabetización en estas edades de acuerdo con el currículum vigente fueron 
tareas descontextualizadas, centradas casi exclusivamente en el aprendizaje del código. He aquí sus términos concretos: "haría que diferenciaran sonidos y letras en palabras que se nombraran", "explicaría el cuento de la letra...", "propondría reseguir letras y palabras con distintos materiales", "les animaría a clasificar y copiar los nombres de los compañeros" o "les propondría dibujar algo que les guste y les invitaría a poner el nombre de lo que se ha dibujado". Estas actividades podrían suscitar interés puntual en un contexto de escritura funcional y significativa, pero resulta obvio que eran concebidas como propuestas generales para aprender a leer y a escribir, con expectativas y resultados homogéneos y con un único fin: que las letras reproducidas fueran aprendidas de forma gradual y progresiva. Se trataba de prácticas que los estudiantes recordaban de su niñez o que habían visto en algunos centros de prácticas y que, afortunadamente, ya no aparecieron en el diagnostico final (tan solo 5 personas siguieron planteando propuestas de este tipo). Con la realización de la asignatura, además, aumentó considerablemente el porcentaje de alumnado capaz de diseñar actividades contextualizadas - en 16 casos también interdisciplinares - con un énfasis en el lenguaje escrito centrado en sus funciones instrumentales (del 16,3\% inicial, integrado por las 12 alumnas de Doble Grado y 1 persona más, se pasó a un 53,1\%). Algunos ejemplos de actividades contextualizadas e interdisciplinares fueron "preparar un debate sobre un tema de interés y anotar las conclusiones", "preparar una fiesta cercana", "preparar un pastel para la merienda", "programar una salida o una visita fuera del aula" y "pensar algún cambio para la organización del aula", todo ello especificando hipotéticos motivos desencadenantes de esas preparaciones y haciendo énfasis en las lecturas y escrituras que originarían. Estas propuestas abordan situaciones reales que podrían emerger de la vida del aula, y sus fines incluyen más de un objetivo y área del currículo. Las propuestas contextualizadas con énfasis en algunos aspectos del lenguaje escrito (C2), como "escribir cartas a los Reyes Magos o a los familiares", "escribir conjuntamente tarjetas postales y felicitaciones para otros" o "generar individual o colectivamente algún producto después de una tertulia literaria", aunque no resulten tan completas, también son contextualizadas, presentan objetivos explícitos y ponen el acento en distintos aspectos del lenguaje escrito. La pregunta que surge aquí, inevitablemente, es hasta qué punto se produjeron cambios conceptuales reales y qué grado de profundidad cabría atribuirles, puesto que, al realizarse el diagnóstico al finalizar el curso y constituir uno de sus medios de evaluación, las respuestas bien podrían estar imbuidas de un consentimiento artificial fruto de tal circunstancia. Asimismo, la mayoría de las actividades (40,5\%) fueran del estilo de "listar los nombres de los participantes del aula", "listar las canciones preferidas", "lo que les gustaría hacer el fin de semana", "hacer inventarios, listados de...", "la utilización la libreta de aula para escrituras privadas" o "escribir 
mensajes para los compañeros"; aunque se enfatizaran las funciones de registro y comunicación del lenguaje escrito, ello muestra una poca contextualización que indica la necesidad de trabajar este factor más a fondo.

Habilidades especificas: 4. Programación de actividades de formación de lectores literarios

TABLA 8. ACTIVIDADES DE FORMACIÓN DE LECTORES LITERARIOS. N ${ }^{\circ}$ DE RESPUESTAS CON PORCENTAJES

\begin{tabular}{|l|l|l|l|l|l|l|}
\hline & $\begin{array}{l}\text { C1: Actividad } \\
\text { adecuada, } \\
\text { explicaday con } \\
\text { objetivos }\end{array}$ & $\begin{array}{l}\text { C2: Actividad } \\
\text { adecuaday } \\
\text { explicada, sin } \\
\text { objetivos }\end{array}$ & $\begin{array}{l}\text { C3: Actividad } \\
\text { adecuada, no } \\
\text { explicada y sin } \\
\text { objetivos }\end{array}$ & $\begin{array}{l}\text { C4: Actividad } \\
\text { no adecuada, } \\
\text { explicada y con } \\
\text { objetivos }\end{array}$ & $\begin{array}{l}\text { C5: Actividad } \\
\text { no adecuada, no } \\
\text { explicada y sin } \\
\text { objetivos }\end{array}$ & C6: NS $/$ NC \\
\hline DI & $3=3,8 \%$ & $9=11,4 \%$ & $31=39,2 \%$ & $10=12,6 \%$ & $24=30,8 \%$ & $2=2,5 \%$ \\
\hline$D F$ & $18=22,8 \%$ & $54=68,3 \%$ & $5=6,3 \%$ & $1=1,2 \%$ & $1=1,2 \%$ & $0=0 \%$ \\
\hline
\end{tabular}

CLAVES - DI: Diagnóstico inicial. DF: Diagnóstico Final. C: Categorización de respuestas. NS / NC: No sabe / no contesta.

A la hora de movilizar didácticamente Donde viven los monstruos, los problemas iniciales del análisis literario previo derivaron en dificultades prácticas para diseñar tareas de formación de lectores con objetivos de aprendizaje definidos. Un total de 36 estudiantes o bien dejó la respuesta en blanco $(2,5 \%)$ o bien propuso actividades no adecuadas - que prescindían de la obra para tratar de forma inmediata el tema del miedo infantil o trabajar plásticamente, en estrecha relación con él, la figura del monstruo -, ya fuera con o sin explicaciones suficientes y fines explícitos (12,6\% y 30,8\% respectivamente). A pesar de que más de medio grupo conceptualizó una tarea de lectura, comprensión o extensión vinculada al álbum de Sendak (globalmente adecuada, pues, desde la perspectiva de la educación literaria), su visión igualmente utilitaria de la literatura infantil se manifestó al optar por el uso del libro como medio para canalizar el trabajo con las emociones o los valores. Fallaron mayoritariamente, también, tanto la explicación suficiente para poder poner la actividad diseñada en práctica $(39,2 \%)$ como la definición de sus objetivos de aprendizaje $(39,2 \%$ $+11,3 \%$ ). Solo 3 alumnas de Doble Grado diseñaron una movilización efectiva del libro para la educación literaria de niños de 5 y 6 años. El alumnado, así, demostró una concepción de los libros infantiles como material de apoyo a funciones didácticas externas a la formación de lectores literarios, por un lado, y sus dificultades para relacionar análisis literario y programación de actividades, por otro. Al finalizar la asignatura, solo 2 personas propusieron una actividad no adecuada para la educación literaria, y únicamente 5 no explicaron bastante cómo desarrollar la actividad. Pero la inclusión de fines explícitos de aprendizaje 
derivados de aspectos literarios previamente consignados se limitó a un 22,8\% de respuestas, por lo que un $68,3 \%$ se quedaron a las puertas de una óptima programación. Se debe consolidar, por consiguiente, el trabajo en este sentido.

\section{Conclusiones}

En las últimas décadas, voces de prestigio han reclamado cambios en los planes de estudios de la formación básica de docentes, considerada deficitaria desde diferentes perspectivas en lo que al aprendizaje del lenguaje escrito y la lectura literaria se refiere, (CERRILLO, 2005; PALOMARES, 2015; SELFA; VILLANUEVA, 2015). A esta necesidad responde el diseño de Didáctica de la lengua escrita y la literatura en educación infantil de $3^{\circ}$ del Grado de Educación Infantil de la UAB. En cuanto a su incidencia real en las creencias, los saberes y las competencias del alumnado, la investigación llevada a cabo arroja diferentes conclusiones.

Los sujetos participantes llegaron a la asignatura con un perfil predominantemente instruccional; una ignorancia mayoritaria sobre qué significa formar lectores; ideas sobre el aprendizaje del código asentadas en prejuicios muy arraigados entre la población docente (tales como que lo primero es enseñar las letras y después practicar las grafías - eso sí, con materiales que motiven -, o que primero van la relación sonido-grafía y el dominio de los trazos de las letras, después la formación de palabras y posteriormente su comprensión); conocimientos sobre literatura infantil prácticamente reducidos a los cuentos populares; importantes limitaciones en cuanto a análisis de producciones infantiles y literarias y programación subsiguiente de actividades, y, en conjunto, una visión distorsionada del trabajo con la lengua escrita y los libros infantiles en las aulas. En pocos meses, sin embargo, tomaron consciencia de sus prejuicios y de los tópicos que éstos contenían; incorporaron la comprensión de cómo los niños se apropian progresivamente el código escrito y de qué es la educación literaria; adquirieron un saber considerable sobre los libros para las primeras edades; incrementaron sus recursos de análisis de producciones escritas infantiles y literarias y de programación subsiguiente de actividades, y, globalmente, afinaron su visión del trabajo escolar con la lengua escrita y la literatura. El alumnado asimiló, en resumen, los principios socio-constructivistas del aprendizaje lingüístico y las bases esenciales de la educación literaria, además de adquirir y ser capaz de aplicar las herramientas clave de ambos. Los estudiantes consiguieron entender mejor la actividad mental del aprendiz y la 
relevancia de sus experiencias de contacto con el lenguaje escrito y la literatura en contextos de aula ricos en situaciones e interacciones que fomenten sus usos práctico, científico y literario; devinieron más capaces de abordar esta tarea en toda su complejidad tanto por lo que respecta al desciframiento del código y sus estrategias de comprensión y producción como al uso de los libros infantiles como material esencial para la formación de lectores; apostaron porque los niños se enfrenten siempre a textos con sentido dentro del sistema de actividad generada en la escuela y en el marco de actividades relacionadas con los usos reales de la lengua escrita; descubrieron el mundo de la literatura infantil para las primeras edades y el proceso de aprendizaje del lector literario, y adquirieron metalenguaje preciso (dejando, por ejemplo, de equiparar "cuento" a literatura o libro). Modificaron, en definitiva, la base de sus concepciones didácticas, transitando progresivamente de un perfil instruccional a un perfil situacional, desestimando el uso estrictamente funcional de los libros infantiles y percibiendo la forma adecuada de situarse para ejercer de mediadores.

A pesar del progreso que esto significa, la investigación también ha puesto en relieve la necesidad de revisar o reajustar diferentes aspectos de la asignatura. En primer lugar, se debería conseguir que el alumnado conociera más profundamente las capacidades infantiles y asumiera la proactividad de los niños cuando el aula se constituye en un contexto letrado donde interactúan habitualmente con los adultos, los libros y otros productos escritos reales. En segundo lugar, habría que enfatizar (experimentalmente a ser posible) el carácter mediador del docente para contrarrestar el protagonismo predominante que el alumnado sigue atribuyendo a esta figura a causa del peso de la tradición escolar y de las propias experiencias. En tercer lugar, se tendría que reforzar el análisis de las obras literarias infantiles con un trabajo interpretativo pormenorizado que mejorara la comprensión del sentido de cada componente dentro de la propuesta literaria que lo incluye. Y finalmente, habría que ejercitar más tanto la inclusión de la contextualización en el diseño de tareas de escritura como la definición explícita de objetivos de aprendizaje en la programación de actividades de educación literaria. Ello implica que la asignatura Didáctica de la lengua escrita y la literatura, único curso obligatorio en la materia de la formación básica docente que se ofrece al alumnado del Grado de Educación Infantil de la UAB, cumple sus fines generales pero presenta algunos puntos débiles que hay que ajustar.

Por lo que respecta al presente trabajo, el estudio de los resultados efectivos de Didáctica de la lengua escrita y la literatura en educación infantil constituye una aportación a la investigación sobre formación básica docente porque prueba en qué una preparación que tiene como base y desarrolla en la práctica los principios del socio-constructivismo y la educación literaria contribuye a incrementar, ampliar y mejorar los conocimientos generales y las habilidades 
específicas relativas a la enseñanza y aprendizaje de la lectura, la escritura y la lectura literaria de los futuros maestros de niños de 0 a 6 años. Esta aportación, sin embargo, viene limitada en su representatividad por estar centrada en un solo grupo, en un solo año académico, en una sola asignatura y en una sola universidad; es decir, por tratarse de un estudio de caso muy acotado. Sería recomendable, pues, replicar la investigación en otros grupos y años para contrastar datos y ofrecer un panorama más exacto de los efectos de la asignatura de la UAB en diferentes promociones de estudiantes. Por otra parte, también sería conveniente comparar el programa de Didáctica de la lengua escrita y la literatura en educación infantil y su despliegue efectivo con los de asignaturas paralelas de otras instituciones académicas. Y, muy en especial, seguir a los sujetos participantes del estudio en su llegada a las aulas para comprobar si esta formación se refleja o no en su acción docente, que es lo que interesa. Investigaciones de este tipo complementarían de manera significativa la contribución del presente artículo, cuyos resultados, no obstante, apuntan sin duda un camino a seguir en la adecuada dirección de la formación básica en lengua escrita y literatura del profesorado de educación infantil.

\section{REFERENCIAS}

BOMBINI, Gustavo; LABEUR, Paula. Escritura en la formación docente: los géneros de la práctica. Enunciación, v. 18, n. 1, p. 19-29, 2013.

CARDOSO, Beatriz; SEPÚLVEDA, Angélica. Entrar na cultura escrita pela porta da literatura infantil: reflexões a partir da pesquisa sobre a compreensão e os usos dos materiais educativos. In: CORREIA BAPTISTA, Monica et al. (Coord.). Literatura na educação infantil: acervos, espaços e mediações. Brasilia: MEC, 2015. p. 81-105.

CERRILLO, Pedro C. Los nuevos lectores: la formación del lector literario. In: UTANDA, M. C.; CERRILLO, P.; GARCÍA PADRINO, J. (Coords.). Literatura infantil y educación literaria. Cuenca: Universidad Castilla-La Mancha, 2005. p. 133-152.

CERRILLO, Pedro C.; YUBERO, Santiago. Qué leer y en qué momento. In: CERRILLO, P.; YUBERO, S. (Coords.). La formación de mediadores para la promoción de la lectura. Cuenca: Universidad Castilla-La Mancha, 2007. p. 237-244.

COLOMER, Teresa. Andar entre libros. México: Fondo de Cultura Económica, 2005.

COLOMER, Teresa. La literatura infantil: una minoría dentro de la literatura. In: CONGRESO INTERNACIONAL DE IBBY, 32., A FORZA DAS MINORÍAS, Santiago de Compostela, 8-12 Set. 2010. Actas... Madrid: OEPLI, 2013. 
COLOMER, Teresa; DURAN, Teresa. La literatura en la etapa de Educación Infantil. In: BIGAS, Montserrat; CORREIG, Montserrat (Orgs.), Didáctica de la lengua en Educación Infantil. Madrid: Síntesis, 2001, p. 213-249.

CORRERO IGLESIAS, Cristina; REAL, Neus. Educación Infantil y trabajo por proyectos: SDs de literatura para las primeras edades. Fronteiraz, n. 17, p. 60-80, 2016.

CORRERO, Cristina; REAL, Neus (Orgs.). La literatura a l'educació infantil. Barcelona: Associació de Mestres Rosa Sensat, 2017.

CREMIN, Teresa; BEARNE, Eve; MOTTRAM, M.; GOODWIN, Prue. Teachers as Readers in the 21st Century. In: STYLES, Morag; ARIZPE, Evelyn (Orgs.). Acts of Reading: Teachers, Text and Childhood. Stoke-on-Trent: Trentham Books, 2011, p. 201-218.

DELEUZE, Gilles. Futurs instituteurs et faibles lecteurs: réalité et/ou fatalité ? Enjeux, n. 74, p. 93-100, 2009.

DÍAZ ARMAS, Jesús. Lectura literaria y formación inicial: creencias del profesorado en formación sobre el texto y su lector. In: MENDOZA, Antonio. (Coord.). Textos entre textos: las conexiones textuales en la formación del lector. Barcelona: Horsori, 2008. p. $177-190$.

DOMÍNGUEZ, Gloria; BARRIO VALENCIA, José Lino. Los primeros pasos hacia el lenguaje escrito: una mirada al aula. Madrid: La Muralla, 1997.

FERREIRO, Emilia; TEBEROSKY, Ana. Los sistemas de escritura en el desarrollo del niño. México: Siglo XXI, 1979.

FONS, Montserrat. Leer y escribir para vivir. Alfabetización inicial y uso real de la lengua escrita en el aula. Barcelona: Graó \& La Galera, 2004.

FONS, Montserrat: PALOU, Juli (Coords.). Didáctica de la lengua y la literatura en educación infantil. Madrid: Síntesis, 2016.

MORÓN OLIVARES, Eva; MARTÍNEZ AGUILAR, Consuelo. Las dificultades de los futuros maestros ante la LIJ: el ejemplo de Alfanhuí. Impossibilia, n. 8, p. 194-207, 2014.

MUNITA, Felipe. Reading habits of pre-service teachers/Trayectorias de lectura del profesorado en formación. Cultura \& Educación, v. 26, n. 3, p. 448-475, 2014.

MUNITA, Felipe. "Para mí todo eran cuentos": incidencia de la formación docente en las creencias y saberes sobre literatura infantil y juvenil. Catalejos: Revista sobre lectura, formación de lectores y literatura para niños, v. 3, n. 6, p. 102-125, jun. 2018.

PALOMARES MARÍN, Mari Cruz. Literatura infantil y universidad: un estudio descriptivo sobre la formación inicial del profesorado de Grado en Educación Primaria. Investigaciones sobre lectura, n. 3, p. 44-66, 2015.

PÉREZ PEITX, Mireia. Estudi longitudinal de les creences sobre l'alfabetització inicial de tres estudiants del Grau d'Educació d'Infantil de la Universitat de Barcelona. 2016. Tesis (Doctoral) - Universitat de Barcelona, 2016. 
RÍOS, Isabel; FERNÁNDEZ, Pilar; GALLARDO, Isabel. Prácticas docentes, condiciones de enseñanza y posibilidades de aprendizaje inicial de la lengua escrita. Cultura y Educación, v. 24, n. 4, p. 435-448, 2012.

SÁNCHEZ, Susana; ALONSO CORTÉS, María Dolores (Coords.). Aprendizaje inicial de la lengua escrita: prácticas docentes y conocimientos de los alumnos. Cultura y Educación, v. 24, n. 4, p. 387-474, 2012.

SARDINHA, Maria da Graça; AZEVEDO, Fernando José; RATO, Rosa. Promoção da leitura na escola portuguesa: metodologias e crenças dos professores do Ensino Básico. Investigaciones sobre Lectura, n. 4, p. 25-50, 2015.

SELFA, Moisés; VILLANUEVA, Juan de Dios. La enseñanza de la lectura y la escritura hoy. Entrevista a Ana Teberosky Coronado. Investigaciones sobre Lectura, n. 4, p. 125135, 2015. Disponível em: <http://www.redalyc.org/articulo.oa?id=446243922008>. Acesso em: 15 fev. 2018.

SHAW MASSENGILL, Donita; DVORAK, Marcia J.; BATES, Karen. Promise and Possibility - Hope for Teacher Education: Pre-service Literacy Instruction Can Have an Impact. Reading Research and Instruction, v. 46, n. 3, p. 223-254, 2007.

SILVA-DÍAZ, María Cecilia. La formación de los maestros en literatura infantil: un estudio diagnóstico. Cuatrogatos: Revista de Literatura Infantil, v. 5 y 6, 2001. Disponível em: $<$ https://www.cuatrogatos.org/docs/articulos/articulos_665.pdf $>$. Acesso em: 11 mar. 2018.

TEBEROSKY, Ana. De la literatura al aprendizaje del lenguaje y su escritura. In: COLOMER, Teresa; FITTIPALDI, Martina (Orgs.). La literatura que acoge: inmigración y lectura de álbumes. Barcelona: GRETEL - Banco del Libro, 2012, p. 239-250.

TOLCHINSKY, Liliana. Lo práctico, lo científico y lo literario: tres componentes en la noción de alfabetismo. Comunicación, Lenguaje y Educación, n. 6, p. 53-62, 1990.

WARMACK, Wanda L. Elementary Education Pre-Service Teachers'Attitudes Towards Reading. 2007. Tesis (Doctoral) - Auburn University, 2007.

WOLLMAN-BONILLA, Julie. Outrageous Viewpoints: Teachers' Criteria for Rejecting Works of Children's Literature. Language Arts, v. 75, n. 4, p. 287-295, 1998.

Texto recebido em 08 de junho de 2018. Texto aprovado em 08 de agosto de 2018. 